https://helda.helsinki.fi

\title{
Care Horizons and Career Choices for Women Managers
}

\section{McKie, Linda}

$2021-11$

McKie , L \& Jyrkinen, M 2021 , ' Care Horizons and Career Choices for Women Managers '

, International journal of care and caring , vol. 5 , no. 4 , pp. 685-700 . https://doi.org/10.1332/239788220X16081401

http://hdl.handle.net/10138/338854

https://doi.org/10.1332/239788220X16081401963947

unspecified

acceptedVersion

Downloaded from Helda, University of Helsinki institutional repository.

This is an electronic reprint of the original article.

This reprint may differ from the original in pagination and typographic detail.

Please cite the original version. 
Linda McKie and Marjut Jyrkinen

International Journal of Care and Caring

Version 12.12 .2020 of the article before proofs:

\section{Care horizons and career choices for women managers}

\section{Introduction}

The need for care extends across the life course and with longevity, the potential period of co-morbidities combined with a restricted quality of life, has increased. At times policies and services may offer support but often, women and their families are stitching together patchwork quilts of care provision (Balbo and Nowotny, 1986; McKie et al., 2002). Those in caring and family support roles are generally in employment and encouraged to work for as long as they can to enhance household income and financial security (Daly, 2018). Households seeking to reconcile caring, working and income generation are finding it a deepening challenge in an era of constrained economic opportunities (Ólafsson et al., 2019). Further, recent public health emergencies, such as Covid-19, have intensified the complex and fragile interweaving of caring and working (Tunstall, 2020; Wolski, 2020).

In this article we present the analysis of data from a study with mid to later career women managers working in Finland and Scotland. Women shared ideas about and experiences of care, notably the current or future implications of elder care, and anticipated this as a potential and further hurdle in considering career options. Concerns were voiced about juggling caring and working and the interweaving of caring across the generations as well as locations. Alongside the expressions of a sense of duty to care, women participants voiced a sense of contentment generated through being there for relatives in their final days. 
Finland and Scotland have several geographical, social, and political parallels. Populations are similar at just over 5 million with a concentration of almost $70 \%$ residing in one large urbanized zone of each country: in Finland, the Helsinki Metropolitan Area and the cities in southern-mid Finland; in Scotland the 'Central Belt' that runs between the cities of Edinburgh and Glasgow. The governments of both countries are negotiating a period of population ageing, as well as wider economic and social changes: families and relationships are shifting with divorce, serial monogamy, co-habitation, family re-formation and an increase in solo living. The health and economic impact of Covid-19 adds a range of health, care and work pressures for families and governments. Brexit also adds a further challenge to provision of caring services and policy support in the UK/Scotland, in part due to immigration regulations limiting mobility for a lower paid care workforce.

Women make up half of the workforce in Finland and in Scotland, but $81 \%$ in Finland work full-time while this is the case for $59 \%$ of Scottish women (Asikainen et al., 2018; Scottish Government, 2007). The contrast in part- or full-time working is in large part due to the Finnish provision of universal day care, itself an historical legacy considered necessary due to a diminished male labour force at the end of World War II. The Finnish parental leave system enables either of the parents to stay home until their child is three years old, and the other parent to work in the meantime. However, less than $10 \%$ of parental leave days are used by fathers (Kela, 2017). Greater regulation of workplaces in Finland is also evident in equality and diversity legislation. For instance, organizations employing 30 or more workers must, by law, have an equality plan in place. The image of Finland having a relatively gender-equal society does, however, cloak high levels of gender segregation in the labour market in which, 
as in Scotland, women are overrepresented in lower paid caring and service forms of employment. Working part-time in Scotland is strongly linked to the presence of dependent younger children with women returning to full-time working and career development at a later stage than in Finland. The Finnish labour market is the sixth most gender segregated in the EU-27, with women dominating public sector jobs and men the private and public sectors in construction work, logistics and traditional manufacturing industries. Similar trends exist in Scotland, but the UK is 20th in this ranking having witnessed change in the opposite direction to Finland concerning gender segregation, which also reflects the dominance of financial and service sectors in the UK economy. In both countries, notable gender pay gaps exist. Further, the UK/Scottish approach to employment regulation is based upon less on legislation and more on guidance, incentives, and encouragement to pursue equality and inclusion goals. Nearly $40 \%$ of employees have a woman as their immediate superior in Finland, which is the highest rate in the EU. In the UK, this figure is $34 \%$, and the average in the EU is $24 \%$ (ParentThirion et al., 2007). Of managers, women comprise 36\%in Finland and $37 \%$ in the UK, the average in the EU being 36\%; of executive leaders women comprise $18 \%$ in Finland, $19 \%$ in the UK, as the average in the EU was $17 \%$ in 2017 . Women managers in both countries are overwhelmingly working full-time, and if parents their children are generally of an age and stage when they are more independent (McCarthy, 2019).

This article offers a contribution to the analysis of gender, care and working by illuminating how care considerations are both omnipresent and interweaving at all stages of a woman's career. We open with a review of research on care and caring across the lifecourse and, subsequently elder care and careers. The methods, data collection and analysis are then considered with our analysis of data presented across three sections, namely, sharp ends and 
juggling acts; temporal perspectives on gender, care and work; and lastly an exploration of data on the spaces through which women consider and deliver care. In the discussion section, we reflect on women managers' position as caring citizens and workers, noting how the realities and anticipations of care continually impact on work and careers, and emphasise the importance of care as a societal issue and one urgently in need of decoupling from an assumed naturalness with women and femininities.

\section{Care and caring across the lifecourse}

Human flourishing is predicated on care and caring; the generally taken for granted and invaluable activities which offer emotional and practical support. Recognising the rhythms of care and caring across the lifecourse, and the interweaving of unpaid family care and paid care services over time and space, the analytical framework of caringscapes offers potential to explore the various dimensions of caring and working (McKie et al., 2002: 915) which covers

planning, worrying, anticipating, speculation, prioritizing, assessing the quality of care, accessing care, controlling care, paying for care, shifting patterns of work, job (in)security, the potential for promotion, moving home, managing family resources, supporting school work, being involved in the school or care group and so on.

Speculating, anticipating, and engaging in care and caring is intrinsic to our lives. We flourish due to the combined forces of family, and institutional forms of care, which ensure transitions to adulthood and engagement in the labour market. As Moen and DePasquale (2017: 49) assert our lives are 'shaped by social norms and structures, including those embedded in systems of unpaid and paid care.' A key assumption is the gendering of care and assumptions among families and institutions that women will provide much of family care regardless of their employment status and form most of the workforce in care and related jobs. Care needs shift across the life course; for example, childcare generally diminishes over time whilst elder 
and sick care can be unpredictable, prone to crises and ends with death. All care work combines the practical with the emotional and at times elder care can be especially draining both physically and psychologically.

The illnesses of old age, the improvement in our ability to live with these, chronic conditions and disabilities, along with increased years of working life, are placing further strains on the provision of care - both formal and informal (Pillemer et al, 2019). Where formal care - state, private or voluntary - is increasingly insufficient, informal carers take up much of the burden while those in need of care are also often simply neglected. It is widely acknowledged that social care needs will increase significantly in the next few decades (International Alliance of Carer Organizations, 2018). Globally, stakeholders - policy-makers and those in receipt of care, alike - show a preference for informal care received in the recipient's home, but the feasibility of this is being hampered by reliance 'on 'trial and error' approaches to carrying out the carer role' (Parkinson et al., 2017: 290). Research has also highlighted the impact of the recent global pandemic and economic downturn coming on top of a decade of austerity measures. For example, Carers Support UK reports a rapid rise in the number of carers leaving employment to care - a $12 \%$ increase over 5 years - or juggling employment and unpaid care (Carers UK, 2019: 5). Its recent annual survey also reveals that $72 \%$ of UK carers report mental ill health due to caring (Carers UK, 2019: 6), and according to its 2016 State of Caring report, in not recognising themselves as carers, many are missing out on vital support; all too often carers comment that 'care is just something you do' (Carers UK, 2016: 3). 


\section{Elder care and careers}

The point at which old age starts is no longer clear, but in the view of many commentators, it starts in the eighth decade of life (Ben-Galim and Silim, 2013), with the need for care generally concentrated in the last five years of life. In most economies, workers are generally encouraged to continue in employment to their late 60s, and thus many women are renewing focus on their careers in midlife. However, this is also a point at which parents, relatives, friends and neighbours, may be entering a period of intense care needs and support.

Informal carers often comment how they have an 'antenna' ready to pick up on any crises in providing and managing care, and how these thoughts and anticipations are ever present in their lives. States of feeling vary widely in terms of intensity, duration, consistency, and valence. There are so-called basic emotions (for instance, love, joy, sadness, anger); social emotions (such as shame, guilt or jealousy), as well as such related constructs as affect, sentiments, and moods (Ashforth and Humphrey, 1995). Pillemer et al. (2019) have considered the dynamic and conflicting emotions about caring and developed the notion of 'intergenerational ambivalence.' They note how changing from one status position to another, for example, from carer to worker, necessitates a shift in role, circumstances and can challenge levels of confidence.

Choices about caring and working are restricted by the parameters of social class, income, and over-riding all of these, the continued presumption of the seemingly natural entanglement of caring and femininity. Policy and research struggle to recognise the complexity of family formation, lifestyles, career and work, and the myriad choices women make. Care becomes individualised especially in times of recession - budget cuts in social 
security, the growth in insecure contracts of employment, slow or no growth in salaries and pension entitlements, increased care and domestic responsibilities - the multiple pressures that many workers, most often women employees, are obliged to live with (Jupp et al., 2019).

Obligations traverse distances bounded by a familial sense of duty evident across time and space. Coe (2016) has illuminated how women synchronize their life courses with the ageing of others in her social anthropological study of Ghanaian migrant women. As migrant women reach middle age, they opt to return home to provide elder and childcare, some leaving wellpaid managerial level jobs. Even across transnational contexts Coe (2016) identifies how time and timing ensures that family care needs are ultimately prioritised for migrant women. What Coe (2016: 44) terms 'entrainment' illustrates how the gendering of power, opportunities and care ensures that adult women will slot into elder care roles in exchange for the support of other relatives. By contrast male relatives, whose power and leverage ensures they achieve higher earnings and thus remittances to send back home, are less likely to be asked to return home. Mobility, and the distance from family members also adds to challenges in delivering and organizing care. Technologies enable keeping in touch and offer opportunities to 'care' at a distance, within and across countries, but also of always being available for work and to 'care'. Numerous dimensions of home, family and work, coalesce across time and space and are evident in 'entwined becomings' (Jupp et al., 2019: 59) which for women are generally multi-layered, often driven by care responsibilities, care needs and domestic labour.

Set alongside diminishing and increasingly costly services, the choices for families can be stark with care issues remaining stubbornly feminised and generally presumed to be the responsibility of adult women and relatives. Occurrences of unanticipated care crises expose 
what have been termed 'care precarity' in many working households. Further, research on age and ageing has highlighted many forms of prejudices and discrimination towards 'older' workers (Desmette and Gaillard, 2008; Irni, 2009; Moore, 2010). Thus, there is a dilemma resulting from the temporal flows of more years in employment, increasing and dynamic care responsibilities and the distances across which caring and working may need to take place.

\section{Methods, data collection and analysis}

Our data are drawn from four focus groups with two conducted in each country. The focus groups were undertaken as the second stage of an Academy of Finland funded research project with the overarching aim of exploring women managers' experiences of their working and family life, and the current and anticipated progress of their managerial careers (Jyrkinen, 2014). The focus groups followed the analysis of 25 semi structured interviews, again undertaken in both countries and the prompts used during the focus groups were drawn from the analysis of interview data.

\section{Why focus groups?}

Focus groups offer opportunities for both the identification of issues, as well as deeper exploration of these as discussion progresses. However, there is also the risk that participants will seek peer approval especially if they know each other or raise personal issues or perspectives likely to cause disruption (Breen, 2006). Aware of the opportunities and potential drawbacks we chose this method with the aim of encouraging exchanges on issues raised in the interviews and exploring how women might share and debate their experiences and anticipations. Further, focus groups allowed us to discuss issues with a range of busy managers and in the light of access challenges in the first stage given domestic and caring 
responsibilities in addition to work. We also found that focus groups encouraged conversations amongst women who did share and reflect upon past and present experiences as well as exploring futures (Barbour, 2018).

The composition of our focus groups reflected a degree of familiarity of those known to each other through business networks and others in which women had never met. We appreciate that some bias may have resulted, especially amongst those who were engaged in networks but in our analysis we found that in those groups there was less time in introductions and more depth offered in relating and sharing experiences. These findings echo those of Wilkinson (2004) who suggests that with prior knowledge participants may feel more comfortable in revealing and discussing personal and sensitive issues. Further, Bryman and Bell (2007: 523) argue that the recruitment of people from 'naturally' formed relationships or groups may lower the artificiality of the research experience. However, after the first 15 minutes there was no tangible difference in the nature and depth of issues raised across the groups.

\section{Recruitment and participants}

We recruited participants through business organizations and work-related networks with women self-identifying as middle managers. The research team approached business networks and companies across several private, public, and charitable sector organizations. We undertook purposive sampling given our aim was to recruit women at a particular stage of their career. Once agreeing to be part of the study participants were contacted by email or letter, and written consent was sought and agreed upon. Anonymity in the data and 
confidentiality with regards participation were assured. We also noted that they may know others through networks and that they could withdraw at any time.

In Table 1, below, we summarise the main characteristics of the focus groups and participants. Women had been or were in relationships, had experience of child, partner or other forms of care, with half having experience of elder care. Participants had been employed in a variety of workplaces as their careers evolved. Whilst working in differing countries, and therefore with access to country and company specific employment policies and practices, most of these policies adhered to European Union overarching economic and social policy frameworks. Ages ranged from early 30 s to mid-50s reflecting the differing flows of careers and career breaks on the opportunities for different generations of women to care, work, and develop managerial careers. Here we can also see a difference between Finland and Scotland with the groups in Scotland comprising older age groups. This reflects the limited availability in the UK of publicly free or low cost care facilities and services for early years. In previous decades this has resulted in women working part time or interrupting careers often for several or more years and hence Scottish participants reaching middle management in their late 40 s or 50 s.

INSERT TABLE 1 ABOUT HERE

Twenty-two women took part in this component of the project. The two focus groups conducted in Finland included women in telecommunications (FG1) and electronics and engineering (FG2), both of which continue to be male dominated sectors. Participants in the two Scottish focus groups did not work in the same organizations but knew of each other 
through business networks. In a charitable sector group (FG3), participants included women managers from non-governmental organizations and charities. Women in the fourth group (FG4) worked in a range of service industries in varying capacities, including as business partners, managers or outright owners of small to medium sized companies.

\section{Data collection and analysis}

Drawing upon the literature, interviews in stage one and pilot work, we identified three main themes for prompts, namely:

- Career development and progress

- Experiences of being a middle manager

- Futures and career aspirations

These themes were introduced in an open-ended fashion with the focus groups lasting between 90 to 150 minutes. With agreement, the discussions were tape-recorded, transcribed by a professional transcriber with whom a confidentiality agreement was made, and in the case of FG1 and FG2, summaries translated into English by the second author.

As noted above we were mindful of group dynamics and the potential for bias or 'group-think' (Rose, 2011), that is, where the group participants lean towards conformity and avoidance of disagreements and are dominated by one or more participants or silenced among others. Our role was one of a moderator and observer to aid and promote an ease of flow in group conversations and to ensure participation across the group (Barbour, 2018). Through our analysis and reporting of data we reflected on tone and the broader context to discussions, noting these as appropriate. In summary, through interactions in focus groups we can identify 
and explore the evolution of career and care experiences as well as the construction of meanings and knowledge as these were debated amongst women.

Our analysis was predicated upon and adapts Rosenthal's (2004) approach and we read and coded using 'textual sorts', namely:

- Description such as daily routines, how these have changed and anticipation for the future.

- Narration in which a linked sequence of past event is related to each other using temporal links, and which participants challenge, agree with or move across challenge/agreement.

- Argumentation which is defined as the reasoning and theorising of general ideas; for example, career changes, decisions on training, relationships in the workplace and outside (ibid.).

The authors read the transcripts independently to develop an initial coding scheme and refined this through analytic conversations.

In the following three sections, we introduce themes from the analysis drawing out the similarities and differences and show that the care by many women managers is present in many ways, including care for those they work with and line manage.

\section{Sharp ends and juggling acts}

Across the focus groups, the gamut of emotions and physical tasks associated with clusters of care and domestic labour emerged early on as evidenced by these texts from FG3: 
Hannah: It's juggling, I actually think, ... my Mum became quite ill and we thought I'd [have to give up work]... I think most people I know who have got families that the balance [of care issues] has changed enormously. .... I don't see nearly as much debate about caring for elderly or children with disabilities that's a real sharp end, because there is so much less out there [services] to utilise.

Lauren: That's the age I dread [older age] and I can see it coming towards me. I mean thankfully our parents are of generations that live longer, and live healthier lives [than in the past], but they don't live forever! I know there will be a point at which, because l've a very small family, you know where's the buck going to stop? And you're just thinking when is that going to be? And how hard is that going to be?

The words juggling, balance, sharp end, dread and stop are indicative of a dynamic and multifaceted range of thoughts and experiences - women were anticipating their 'care futures' drawing upon temporal and spatial perspectives. The tone was simultaneously resigned, breathless, anxious and ultimately pressured. There was also an element of anticipatory energy as with Lauren posing three questions at the end of her contribution, namely where, when, and how with regards to elder parents' care. There was also an awareness of diminishing support from public or charitable organizations in both countries. Support from extended family members was discussed as a source of emergency care and in conjunction with public or paid for services. Examples of emergency care situations for elders, for example, falls, strokes or heart attacks, were markers of declining health and suggested a need to take stock of life in general. As unpartnered women felt responsibility to care for their parents, it was interesting to notice that women in partnerships felt obliged to care and 
organize care for both parents and in-laws: but they did not raise up the responsibilities of men as carers for even their own parents. Regardless of relationship status, women also spoke of their need to be present for those they line-manage too, evidencing the intertwining webs of care at work.

Jane in the service sector group (FG4) had put her business plans to one side:

Jane: I had worked for ten years until last year with [name of organization] and because of the recession, I was made redundant. Good opportunity for me to set up as a freelancer I thought. But then my mother suffered a massive stroke. I had to abandon that, and she was in hospital for eight months. It is only recently that I've just been able to sort of re-join the labour market and I'm working part-time with [new organization] just to see how it goes and whether or not I can plan longer term.

As women listened to Jane's story there was silence along with nods potentially of support. Several women jumped in to congratulate Jane on supporting her mother, and subsequently regaining a foothold in the labour market. Across this discussion, the speech was gentle in tone and responses might be analysed as women supporting each other, especially Jane, whilst reflecting on the possible implications for themselves. When the conversation started up again it considered the issue of time and of waiting for plans to emerge but that crisis and events can sweep away these plans.

Current elder care situations were reported to be relatively isolated and isolating and somewhat in contrast to the hectic times of childcare. Women spoke of leading in the organization of care arrangements and being the first point of call in an emergency for both 
child and elder care. These presumptions about gender and roles, as mothers and daughters, whether partnered or unpartnered, were not directly challenged, but rather spoken about in terms of resignation and, on occasions, even with frustration. Partners, adult children, and other relatives were referred to as 'support' for specific tasks such as collecting children from school, shopping for an elderly relative, or driving an ageing parent to an appointment. These activities were important, but did not offer over-arching inputs to organizing care across time and space. Interestingly, partners and male relatives were absent from these discussions.

\section{Temporal perspectives on gender, care, and work}

There was, as noted, an assumed naturalness to caring and working, that ran across women's adult lives. One example is in FG2:

Ella: I am terrified to see how my mother is ageing. I'm thinking when I will get some kind of emergency bracelet for her. Already she forgets whether she is on her way to the shops or on her way back home [timid giggle]; so, this is the situation. But you somehow try to postpone thinking about these things. I am not a nursing type at all. My husband jokes that if I was a nurse, I would give aspirins to all the patients and tell them to be quiet and stop whining. [laughter in the group]

Sara: My Mom is 82 years old and lives on her own, and she constantly says that she does not want to be burden to anyone...

Aino: I want to be a burden! [laughter in the group]

Sara: ....and so although I am a kind of nursing/caring type, I doubt that I would quit my career [if an elderly relative become ill]

Liisa: I think that women have a stronger care instinct than men.

Olivia: Right. 
The discussion progressed with many agreeing that women have a 'care instinct' and the association of care with nursing further evidences how conversations assumed a naturalness of femininities and caring in both the private and public spheres of life (Sevenhuijsen, 2007). No one in the groups challenged the presumed association of femininities and care - although Ella (FG2) had admitted that she is not necessarily a 'nursing type'. Many hummed in agreement or nodded their heads in response to the statement by Liisa that 'women have a stronger care instinct than men'. Ella went on to note that she would just get on with 'what was needed'. She was not alone in expressing an inevitability about care leadership, and to undertake this along with a demanding job and domestic responsibilities. Women anticipated the ageing of those around them as well as of themselves. These anticipations evoke the interdependencies across generations, within households and families. It was also noted that the impact of health developments and changes in fertility may place further pressures about adult women working and caring.

Experiences of, and speculations about, caring futures were juxtaposed by women who shared examples of current or previous negotiations, flexible working and care arrangements in their role as managers. Negotiations included care leaves for maternity, paternity, and compassionate and flexible working. Several women asserted that both male and female colleagues preferred to approach female managers to discuss care arrangements, which reinforced the seeming naturalness of femininities and care. These comments echo the analysis of Anttonen et al. (2009: 37) that caring and dependency are not in the forefront of traditional masculinities, and caring is work undertaken by female partners, mothers, sisters or other women as paid care workers. 
In summary, across the focus groups women spoke of the challenges of combining working life, career advancement and care; their caring and career scapes are intertwined during different phases of working life (McKie et al., 2013). They noted that in the current economic context, with a presumption that all adults will work regardless of care responsibilities, positioned them in the ongoing paradox of worker and carer, feeling guilt when they could not juggle both at one and the same time. In addition, there were strongly voiced concerns about being available for colleagues and the people they line-manage who also have caring and working challenges. These were spirals of caring and working with the woman manager generally seeking to address the needs of others and latterly themselves.

\section{Considering and delivering care across a multiplicity of spaces}

In recent decades, socio-economic and labour market changes have led to notable mobility in education, training, and employment opportunities. Generations often live at a distance from each other, and sometimes across continents (Coe, 2016). As noted earlier the concentration of populations around capital cities results in many women managers living at distance from their parents. These changes generate a new set of challenges for the organization and delivery of care and careers as evidenced in FG3:

Lauren: ... my Mum's hundreds of miles away and I'm thinking... [what does the future hold]... I know quite a senior woman in the Civil Service who every month had to take a flight of an hour to sort out her 90 -year-old mother who was living by herself. Each month on a Friday night, she would go down on the plane and reconstruct all the support and care mechanisms around her Mum ready for another three or four weeks. And there were phone calls every day to check it all out. I'm just thinking 'Oh Christ'. And I think it's going 
to be like that for a lot of us soon enough. [slight pause] Well not quite, but you know what I mean, there's going to be a mid-generation that's had children later, but they're going to have smaller children and older parents and be further away from their parents.

Lauren spoke with both admiration and bemusement about her colleague caring for a terminally ill mother with the associated travel and constantly monitoring arrangements over the phone. In many ways her ambivalence was evident across many conversations with the move from career manager to carer, posing a range of immediate and longer-term challenges.

Women managers were often in between a so called 'rock and a hard place' (Lauren, FG3) For many, to organize care from a distance was the only option. Several women expressed the view that legislation on flexible working appeared relatively well geared to care for young children, but considered that elder care has a more negative, and less supported status as it is often driven by crises and decline, and intensified rather than dissipated as time went on. Legislation in Finland might be said to represent these differences in that care for a sick child is usually paid for four days, but not in the case of elder care. Likewise, in the UK workers are entitled to take reasonable time off work to deal with unexpected problems or emergencies with close family members; 'dependant leave'. However, workers may not be paid, depending on their contract of employment. There is no set amount of time a worker can request and much depends on the situation and the discretion of the line manager. Childcare and related flexible working arrangements generally reduce as the months and years progress. By contrast, elder care is often highly unpredictable, as it becomes intense, and will result in death, understandably leaving carers and family exhausted and distressed. 
Technology and social media provide opportunities to connect, but can also generate additional pressures as it can be assumed that communications are regular and can take place regardless of location or role. In addition, there can be multiple challenges in the capabilities of older relatives to use technologies. Women managers engaged in elder care spoke of care through online activities, for example, to order food, pay bills, for personal alarm systems and complete applications for insurance and utilities. However, the various media made it difficult to take a complete break from care, and thus whilst elderly relatives might be hundreds of miles away, their care needs were ever present in women's thoughts. Distance was also recognised as a barrier to inter-generational care support as elders are also grandparents and can be a source of unpaid support for children and parents. However, grandparents who live some distance struggle to offer any reciprocity in care especially for grandchildren.

Business travel, central to many managerial roles was also complex and illuminated intergenerational support as illustrated in FG1:

Ellen: ...As I do some travelling and my husband has some work trips too, and our own parents do not live in the same area, then we have to just decide which one of us skips the trip. We evaluate for who the trip is of more valuable.

Paula: ...but when I lived for three and a half years as a single-mother and I had the business responsibility and $R \& D$ responsibility so that I was at work often during nights, weekends and evenings, then it was a lot of wheeling and dealing, as my family lived 500 kilometres away. 
Lotta: Right, this is the difference today. In years gone by families used to live in same area as each other. But now people move for jobs and courses leaving them with a thin support network...

Several women had to travel and drew upon relatives as well as partners for help. Ellen stood out as having a more equal relationship given the way she described the decision-making process for work trips. Most women placed their partner's work first with their care and domestic role as the priority. Refusal to travel or work abroad (Hartl, 2004) was said to have a serious impact on a career, and the discussions of our participants showed how multidimensional, and sometimes frayed ways there are how women manage caring, domestic labour and careers. There was both delight and drudgery, and a depth of emotional labour and love - in care relationships many women struggled across a range of feels, activities and aspirations (see Lynch, 2007). 


\section{Discussion}

Our data evidence the similarities in the experiences of women managers across Finland and Scotland; in summary, the pivotal role of care and caring in forging their everyday and longerterm plans. For example, Liisa asserted that 'I think women have a stronger care instinct than men' and the assumed naturalness of women and caring, which was also evidenced across conversations about women leading on the organizing or scripting of formal and informal care for children and relatives. Career developments and experiences must therefore be set in the context of drawing upon past critical life experiences, the ongoing juggling of caring and working, and anticipations about futures. Contrasts exist between discussions on child-care, generally positive, and the expressed concerns about elderly parents, including the potential for stresses in care relationships, set alongside career ambitions.

Earlier we introduced the analytical framework of caringscapes, through which we might explore multiple experiences and thoughts about caring. The multifaceted ways in which women experienced caring and working - their caringscapes - illuminates the interdependencies between formal and informal caring provision, as well as employers, colleagues, and families. The lens provided by these data brings out the multiplicity of temporal and spatial challenges. Women move across the practical, day-to-day clock time of getting from home to work, through calendar time as exemplified in taking a child or parent to on-going medical investigations and regular check-ups, as well as the experiences, speculations, stresses and expectations which might come together in the decision to take a training course or apply for a promotion (Bryson, 2013). 
As evident in these data, technologies and mobility offers opportunities to be in close connection with those needing care and emotional support, but the potential to be in proximity online or in person may also add to caring and working pressures. The notion of 'scapes' provides a lens to the stormy times and cloudy days in careers and family lives. Thus, women traverse contrasting cultural and organizational nuances, which require manoeuvring through the good times or 'lush valleys' (for example, the joy of a relative's recovery or a job promotion) and the hurdles and setbacks, the 'barren hills' (including, for example, caring for a terminally ill relative or a rejection for promotion), as they develop and live through their caringscapes (McKie et al. 2013; McKie and Jyrkinen 2018; Salminen-Karlsson, 2015).

Previous research as well as our data indicate how women have an antenna for care and express simultaneously their sense of obligation, satisfaction, and fulfilment in caring, whilst also forging a career where they also care for others. Some women spoke of a sense of isolation, of the burden and stress resulting from juggling caring and working. Caring for elders intensifies over time and often at short notice, and whilst debates on care and caring are now high on policy and political agendas, it remains to be seen how services will evolve. Informal care provision is becoming ever more relevant as services remains stretched and are increasingly too costly to access to required levels.

Following a decade of austerity, and now a recession resulting from the impact of Covid-19, women's opportunities will likely stall, and inequalities across race, social class, and location, will deepen. Early research on the implications of Covid-19 has found that women are disproportionately affected with their contribution to the domestic sphere having increased and thus reinforcing an assumed naturalness of femininities and caring. Working from home 
is for many women something of a challenge and less of a benefit. The medium to longerterm impact on careers, and opportunities for promotion, are likely to be notable and potentially negative (Karjalainen and Jyrkinen, 2020). At the same time, Acker's (1990: 1545) assertion some thirty years ago remains relevant today; a redefinition of work is required and one in which '[T]he rhythm and timing of work would be adapted to the rhythms of life outside of work ..... taking care of a sick mother would be as valued as ..... designing computer software.' Women in managerial positions encounter serious challenges and increasingly these include intergenerational care whilst trying to extend periods of financial independence and thus savings for retirement years.

Many researchers and commentators have explored the factors in the slow progression into senior roles for women, and drawn upon the metaphor of a glass ceiling to describe invisible barriers to achieving senior levels. Our analysis suggests that the metaphor of a care ceiling might draw attention to the multiple challenges of child to elder care for women's careers. The causes of a care ceiling are many and multiple. Events can collide, such as the serious illness of a parent at the same time as an offer of promotion; women may place the education or careers of others, before themselves. The spectrum of causes ranges from cultural to the specific, such as the inflexibility of work arrangements, but the result is the continued focus on women as primarily carer citizen in both paid and informal care work. In summary, our data illustrate how women are anticipating and traversing the multi-faceted challenges evident in socio-economic structures and practices. These continue to depend upon, and yet place limited value on, care, and those who provide unpaid or paid care labour (Skeggs, 2014). 
The women in this study are Caucasian, middle class, in full-time work, and so would be considered privileged. With the impact of multiple dimensions of care evident across their working and family lives (McMunn et al., 2020), we would speculate that similar or further challenges face those less privileged who will struggle for the resources and services to address care responsibilities. Recent research demonstrates some changes in middle-class households with men undertaking more domestic and care work, but these shifts are not likely to generate a notable change across societies for many decades to come without major policy-level interventions (McMunn et al., 2020; Kangas, 2020).

Flexible working was considered easier to secure and considered more legitimate to childcare rather than care for other significant persons. Whilst changes in the content of, attitudes towards, and discretion to access flexible working policies are required, men might also be further engaged. Ironically, our experiences of lockdown and working from home, which offered opportunities for a better sharing of care have demonstrated how careers and care remain highly gendered (Wenham, 2020). 


\section{Funding}

The data were collected as part of the second author's post-doctoral project on women managers, gender, and age, funded by the Academy of Finland (2008-2010). The re-analysis of the data and writing of this article took place in part of the Socially and Economically Sustainable Future Working Life (WeAll) project (No 292883), which is funded by the Strategic Research Council (SRC) at the Academy of Finland (2015-2021).

\section{Conflict of interest statement}

The authors declare there is no conflict of interest.

\section{Acknowledgements}

The authors extend their thanks and appreciation to the women who participated in the original project and the organizations who have supported the research. Many thanks for the Academy of Finland (AoF) for funding of the post-doctoral research and the AoF Strategic Research Council funding for the WeAll project.

\section{Table}

There is one table in a separate file 


\section{References}

Acker, J. (1990) 'Hierarchies, Jobs and Bodies: Theory of gendered organizations, Gender \& Society, 4 (2), 139-158.

Anttonen, A. and Zehner, M. (2009) 'Tutkimuksen lähestymistapoja hoivaan', in A. Anttonen, H. Valokivi and M. Zecner (eds.) Hoiva. Tutkimus, politiikka ja arki [Care. Research policy and everyday life]. Tampere: Vastapaino, pp. 16-53.

Ashforth, B. and Humphrey, R. (1995) Emotion in the Workplace: A reappraisal, Human Relations, 48: 97-125.

Asikainen, J., Pietiläinen, M. and Keski-Petäjä, M. (2018) Gender Equality in Finland 2018. Statistics Finland, http://www.stat.fi/tup/julkaisut/tiedostot/julkaisuluettelo/yyti_gef_201800_2018_19723_n et.pdf.

Balbo, L. and Nowotny, H. (eds.) (1986) Time to Care in Tomorrow's Welfare System. Vienna: Eurosocial.

Barbour, R. (2018) Doing Focus Groups. London: Sage. $2^{\text {nd }}$ edition.

Ben-Galim, D. and Silim, A. (2013) The Sandwich Generation. Older Women Balancing Work and Care. London: Institute for Public Policy Research. 
Breen, R. L. (2006) 'A Practical Guide to Focus-Groups Research', Journal of Geography in Higher Education, 30(3): 463-475.

Bryman, A. and Bell, E. (2007) Business Research Methods. Oxford: Oxford University Press.

Bryson, V. (2013) 'Time, Care and Gender Inequalities', in A. Coote and J. Franklin (eds.) Time on our side: Why we all need a shorter working week, London: New Economics Foundation, pp. 55-67.

Carers UK (2016) State of Caring. London: Carers UK.

Carers UK (2019) State of Caring. London: Carers UK.

Coe, C. (2016) 'Orchestrating Care in Time: Ghanaian migrant women, family, and reciprocity', American Anthropologist, 118(1): 37-48.

Daly, M. (2018) 'Policies on Family Support and Parenting Support in a Global Context', in B, Björk Eydal and T, Rostgaard (eds) Handbook of Family Policy, Cheltenham: Edward Elgar, pp. $351-62$.

Desmette, D. and Gaillard, M. (2008) 'When a "Worker" Becomes an "Older Worker". The effects of age-related identity on attitudes towards retirement and work', Career Development International, 13(2): 168-185. 
Hartl, K. (2004) 'The Expatriate Career Transition and Women Managers' Experiences', Women in Management Review, 19(1): 40-51.

International Alliance of Carer Organizations (2016) Global State of Care. Washington: IACO

Irni, S. (2009) 'Cranky Old Women? Irritation, resistance and gendering practices in work organizations', Gender, Work and Organization, 16 (6): 667-683.

Jupp, E., Bowlby, S. Franklin, J. and Hall, S. (2019) The New Politics of Home. Policy Press: Bristol.

Jyrkinen, M. (2014) 'Women Managers, Careers and Gendered Ageism', Scandinavian Journal of Management. An International Journal, 30(2): 175-185.

Kangas, E. (2020) Discourses of Fatherhood in Leadership and Organisations. University of Jyväskylä dissertations 308. Jyväskylä University School of Business and Economics.

Karjalainen, M. and Jyrkinen, M. (2020) ‘Eriarvoistava etätyö’ [Remote work and inequalities]. Blog in http://weallfinland.fi/eriarvoistava-etatyo/ 
Kela (2018) 'Perhevapaat jakautuvat epätasaisesti' [Unequal share of family leaves]. Kansaneläkelaitos - The Social Insurance Institution of Finland, https://www.kela.fi/perhevapaat-tietopaketti (accessed 8.6.2020).

Lynch, K. (2007) 'Love Labour as a Distinct and Non-commodifiable form of Care Labour. The Sociological Review, 55(3): 550-570.

McCarthy, N. (2019) Where Women Are In Management Across The EU. https://www.statista.com/chart/17297/share-of-female-senior-executives-and-managersin-eu/ (accessed 8.6.2020).

McKie, L., Gregory, S. and Bowlby, S. (2002) 'Shadow Times: The temporal and spatial frameworks and experiences of caring and working', Sociology, 36(4): 897-924.

McKie, L., Biese, I. and Jyrkinen, M. (2013) “The Best Time is Now!': The temporal and spatial dynamics of women opting in to self-employment', Gender Work and Organisation, 20(2): 194-196.

McKie, L. and Jyrkinen, M. (2018) 'Early to Mid-Career Women Managers: Experiences of Gendered Age, Care and Work', in A. Broadbridge and S. Fielden (eds.) Research Handbook of Diversity on Careers. Cheltenham: Edward Elgar, pp. 44-59.

McMunn, A., Bird, L., Webb, E. and Sacker, A. (2020) 'Gender Divisions of Paid and Unpaid Work in Contemporary UK Couples', Work, Employment and Society, 34(2): 155-173. 
Moen, P., and DePasquale, N. (2017) 'Family Care Work: A policy-relevant research agenda', Internatioanl Journal of Care and Caring, 1(1): 45-62.

Moore, S. (2010) “No Matter What I did I Would still End up in the Same Position': Age as a factor defining older women's experience of labour market participation', Work, Employment and Society, 23(4): 655-671.

Ólafsson, S., Daly, M., Kangas, O. and Palme, J. (2019) (eds.) Welfare and the Great Recession: A Comparative Study of Europe, Oxford: Oxford University Press.

Parent-Thirion, A., Fernández-Macías, E., Hurley, J. and Vermeylen, G. (2007) Fourth European Working Conditions Survey. Dublin: European Foundation for the Improvement of Living and Working Conditions, https://www.eurofound.europa.eu/sites/default/files/ef_files/pubdocs/2006/98/en/2/ef06 98en.pdf.

Parkinson, M., Carr, M., Rushmer, R., Abley, C. (2017) 'Investigating What Works to Support Family Carers of People with Dementia: Arapid realist review', Journal of Public Health, 39(4): 290-301. 
Pillemer, K., Suitor, J. J., Losada Baltar, A. (2019) 'Ambivalence, Families and Care', International Journal of Care and Caring, 3(1): 9-22.

Radcliffe, E., Lowton, K. and Morgan, M. (2013) 'Co-construction of Chronic Illness Narratives by Older Stroke Survivors and Their Spouses', Sociology of Health and IIIness, 35(7): 993-1007.

Rose, J. D. (2011) Diverse Perspectives on the Groupthink Theory - A Literary Review, https://www.regent.edu/acad/global/publications/elj/vol4iss1/Rose_V4I1_pp37-57.pdf.

Rosenthal, G. (2004) ‘Biographical Research', in C. Seale, G. Gobo, J. F. Gubrium \& D. Silverman (eds.), Qualitative Research Practice. London: Sage Publications.

Salminen-Karlsson, M. (2015) 'Expatriate Paternalistic Leadership and Gender Relations in Small European Software Firms in India', Culture and Organization, 21(5), 409-426.

Sevenhuijsen, S. (2007) Citizenship and the Ethics of Care: Feminist Considerations on Justice, Morality and Politics. London: Taylor and Francis.

Skeggs, B. (2014) 'Values beyond Value? Is anything beyond the logic of capital?', The British Journal of Sociology, 65(1): 1-20.

Tunstall, R. (2020) Covid-19 Policy is Social Policy. Social Policy Association Blog. http://www.social-policy.org.uk/spa-blog/covid-19-policy-is-social-policy/ 
Wenham, C., Smith, J. and Morgan, R. (2020) COVID-19: The gendered impacts of the outbreak, The Lancet: 395(10227): 846-848.

Wilkinson, S. (2004) 'Focus Group Research', in D. Silverman (ed.) Qualitative Research: Theory, Method, and Practice, Thousand Oaks, CA: Sage, pp. 177-199.

Wolski, D. (2020) 'The Role of Social Policies in Times of Covid-19', EUROSociAL https://eurosocial.eu/en/bitacora/el-papel-de-las-politicas-sociales-en-tiempos-de-covid$19 /$ 